\section{Continuous glucose monitoring during the European Soccer cup semifinal, Italy against Holland}

Dear Sir,

It is well recognised that in patients with Type I (insulin-dependent) diabetes mellitus oscillation of blood glucose levels are expected during stressful events (1) Despite tight metabolic control and multiple insulin injections, hyperglycaemia can occur as a consequence of a rapid rise of counter-regulatory hormones, mainly cortisol and catecholamines (2).

Very recently continuous automatic monitoring of blood glucose has been made possible in the subcutaneous tissue (3). The system consists of a Holer-style sensor comprising four components, including a pager sized glucose sensing device with an external electrical connector, a connecting cable, and a communication device enabling data stored in the monitor to be downloaded to a personal computer. Using this system the glucose profile can be accurately characterised both day and night. A man, aged 25 years affected by Type I diabetes with a disease duration of 6 years and with excellent metabolic control over the past 3 months $\left(\mathrm{HbA}_{1 \mathrm{c}}=6.5 \%\right)$, was placed on a glucose sensor (Minimed Inc. Sylmar Calif., USA) between 28 and 29 June 2000. The subject leads a normal life with meal intake at $7.30 \mathrm{am}, 1.30 \mathrm{pm}$ and $8 \mathrm{pm}$ preceded by the subcutaneous administration of 4,8 and $8 \mathrm{IU}$ of rapid insulin, respectively. A fourth injection of $10 \mathrm{IU}$ of intermediate insulin is given at bed time. He monitors his blood glucose at least four times a day so that he is able to make small corrections of insulin doses when required. He also performs regular exercise for 20 min every day, usually in the morning. To sum up, he was the perfect patient in whom to try the glucose sensor expecting near normal blood glucose.

As shown in the figure, the blood glucose profile during the afternoon and evening of first day of the sensor application was good with marginal oscillation of blood glucose levels. On June $29^{\text {th }}$ we detected a rapid increase of blood glucose levels in the early evening from $6 \mathrm{pm}$ onwards reaching the peak at $8: 30 \mathrm{pm}(\mathrm{BG}=302 \mathrm{mg} / \mathrm{dl})$ at the exact time when penalties concluded the thrilling semi-final between Italy and Holland during the recent European Soccer Championship. He did not consume any snacks or drink alcohol during the match as instructed for monitoring purposes. At the end of the match he took his injection of rapid insulin (increased by 5 IU on the occasion) followed by a regular meal and decrease of blood glucose values. There were no differences in other activities (exer-

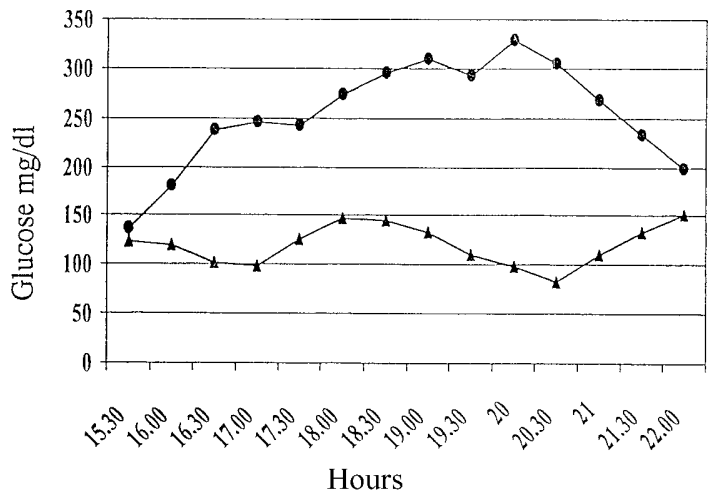

Fig. 1. Monitoring glycaemia with the glucose sensor on two consecutive days one of which coincided (from 18 to $21 \mathrm{hrs}$.) with the semi-final of the European soccer match Italy against Holland. Blood glucose the day of the match -; blood glucose the day before the match

cising or changes in diet) between the two days of the glucose sensor application.

This case demonstrates that the use of glucose sensors allows a precise evaluation of blood glucose profile offering very useful information on the oscillation of blood glucose even in those patients who are recognised to have good metabolic control. Adjustment of insulin therapy to stressful events could then be possible, even though pleasant (the subject was a supporter of the winning Italian team) and unpredictable episodes, such as the one just described, are not programmable, thus limiting the scope for adjustment in insulin therapy.

Yours sincerely,

M.G. Cavallo, S. Romeo, G. Coppolino, P. Pozzilli

\section{References}

1. Surwit RS, Schneider MS (1993) Role of stress in the etiology and treatment of diabetes mellitus. Psychosom Med 55: 380-393

2. Vranic M, Miles P, Rstogi K, et al. (1991) Effect of stress on glucoregulation in physiology and diabetes. Adv Exp Med Biol 291: 161-83

3. Mastrototaro J (1999) The MiniMed Continuous Glucose Monitoring System (CGMS). J Pediatr Endocrinol Metab 12: $751-758$

Corresponding author: P. Pozzilli, University Campus Biomedico, Via Longoni 83, 00155 Rome, Italy 